\title{
Analisis Sifat Mekanik Karet Silikon sebagai Kandidat Prepusium Sintetik pada Alat Peraga Khitan
}

\author{
Muhammad Khafidh*, Abdullah Firdaus, Ilham Akbar Velayati \\ Program Studi Teknik Mesin, Fakultas Teknologi Industri, Universitas Islam Indonesia \\ Jalan Kaliurang KM 14,5 Ngemplak, Sleman 55584 \\ *E-mail: khafidh@uii.ac.id
}

\begin{abstract}
Abstrak
Khitan atau sunat (sirkumsisi) merupakan proses tindakan medis berupa pembuangan sebagian dari kulit luar penis (prepusium) yang membungkus kepala penis (glans). Di Indonesia, khitan banyak dilakukan pada anak laki-laki ketika mencapai masa usia 7 sampai 12 tahun. Tindakan khitan dapat dilakukan oleh berbagai profesi tenaga kesehatan, seperti dokter, perawat, dan mantri sunat. Untuk melatih keterampilan tindakan khitan, salah satu metode yang dapat digunakan adalah dengan menggunakan alat peraga khitan sebagai sarana latihan memotong dan menjahit kulit penis. Tetapi, alat peraga khitan masih minim ditemukan di Indonesia. Salah satu poin penting dari alat peraga khitan adalah adanya kulit sintetis yang sifat mekaniknya mirip kulit asli agar ketika latihan memotong dan menjahit mempunyai feeling yang sama. Penelitian ini bertujuan untuk membuat dan menganalisis sifat mekanik karet jenis silikon sebagai material pengganti prepusium pada alat peraga khitan. Pengujian sifat mekanik dari prepusium dan karet silikon menggunakan Dynamic Mechanical Analyzer (DMA). Hasil penelitian menunjukkan modulus elastisitas prepusium dan silikon mempunyai tren yang sama, tetapi mempunyai nilai eksak yang berbeda. Berdasarkan hasil survei yang dilakukan terhadap beberapa praktisi khitan di Yogyakarta, kulit sintetis mudah dipotong dan dijahit serta mempunyai feeling yang mendekati sebenarnya.
\end{abstract}

Diterima: 22-09-2020; Direvisi: 26-11-2020; Dipublikasi: 28-12-2020

Kata kunci: alat peraga khitan; karet silikon; khitan; sifat mekanik.

\section{Abstract}

Circumcision is a medical treatment to remove a part of preputium which covers the head of a penis (glans). In Indonesia, circumcision is mostly performed when the boys reach the age of approximately 7 to 12 years. Circumcision can be performed by various medical staffs, such as doctors and nurses. To increase the circumcision skills of medical staffs, one of the methods is to use circumcision manikin to practice cutting and sewing processes. However, the circumcision manikin in Indonesia is limited and sometimes do not meet the expectations of the medical staffs. One of the important part of the circumcision manikin is a synthetic preputium which need to has similar mechanical properties compared to the real preputium, so that the medical staffs will have the same feeling during cutting and sewing processes. This study aims to develop and analyze the mechanical properties of silicone rubber as a synthetic preputium in circumcision manikin. The mechanical properties of the real preputium and silicone rubber are analized by using a Dynamic Mechanical Analyzer (DMA). The results show that the elastic modulus as a function of strain for preputium and silicone rubber have the same trend, but have different values. Based on the assesment results of several medical staffs in Yogyakarta, the synthetic material is easy to cut and sew and give. It also gives a similar feeling compared to the reality.

Keywords: circumcision; manikin; mechanical properties; silicone rubber.

\section{Pendahuluan}

Indonesia merupakan negara dengan penduduk muslim terbesar di dunia. Salah satu ajaran Islam yang sudah tidak asing dilakukan oleh masyarakat Indonesia adalah khitan. Khitan merupakan proses tindakan medis berupa pembuangan sebagian dari prepusium yang membungkus glans. Anak laki-laki di Indonesia biasanya dikhitan saat berusia antara 7 sampai 12 tahun. Dalam beberapa kasus, terkadang khitan juga dilakukan pada saat masih bayi. Khitan memiliki banyak manfaat medis bagi tubuh, tetapi manfaat yang didapat juga sebanding dengan resiko trauma yang mungkin dialami anak-anak.

Di Indonesia, khitan dapat dilakukan oleh berbagai jenis profesi tenaga medis seperti dokter, perawat, dan mantri sunat. Dalam proses tindakan khitan, terdapat resiko cedera yang dapat terjadi apabila tenaga medis kurang teliti. 
Beberapa laporan menunjukkan bahwa pernah terjadi kesalahan saat tindakan khitan [1,2]. Untuk mengurangi resiko tersebut, tenaga medis seharusnya dibekali dengan keterampilan secara teori dan praktek lebih intensif dalam melakukan tindakan khitan.

Salah satu cara meningkatkan keterampilan tindakan khitan bagi tenaga medis adalah penggunaan alat peraga khitan yang menyerupai kondisi sebenarnya. Beberapa penelitian menunjukkan bahwa alat peraga khitan dapat meningkatkan pengetahuan dan pengalaman tenaga medis secara signifikan [3,4]. Akan tetapi, alat peraga khitan sebagai tools untuk meningkatkan keterampilan tersebut masih jarang dijumpai di Indonesia. Berbeda dengan produk-produk lain yang dibanjiri oleh produk dari Tiongkok, alat peraga khitan produk Tiongkok tidak ditemukan di pasar Indonesia. Hal ini dimungkinkan karena khitan adalah sesuatu yang asing di Tiongkok. Oleh karena itu, Indonesia mempunyai peluang besar untuk mengembangkan produk alat peraga khitan sehingga dapat memenuhi kebutuhan alat peraga khitan di dalam negeri.

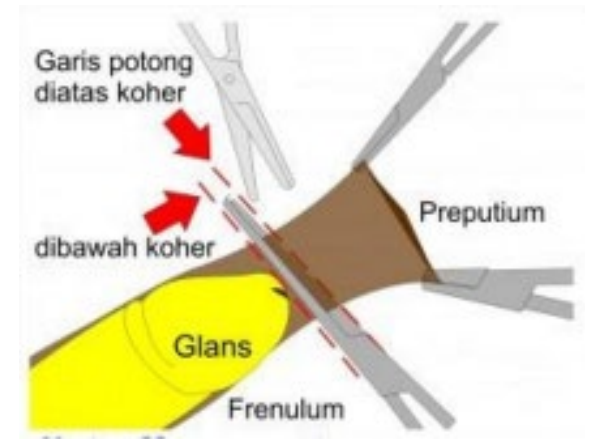

Gambar 1. Teknik sirkumsisi [5].

Bagian terpenting dalam alat peraga khitan adalah kulit sintetis pengganti kulit penis, khususnya bagian prepusium yang akan dipotong, lihat Gambar 1. Sifat mekanik yang mirip antara kulit sintetis dan kulit asli akan membuat tenaga medis mempunyai pengalaman yang sama saat melakukan latihan tindakan khitan.

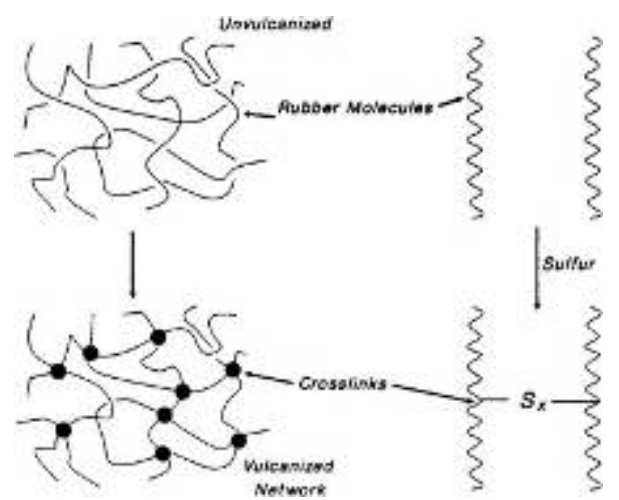

Gambar 2. Rantai polimer dan crosslink pada karet [6].

Kulit adalah lapisan atau jaringan yang menutup hampir seluruh tubuh dan melindungi tubuh dari bahaya yang datang dari luar. Lapisan kulit di semua bagian tubuh pada dasarnya sama dan mempunyai ketebalan bervariasi mulai dari $0.5 \mathrm{~mm}$ sampai $5 \mathrm{~mm}$ [7]. Beberapa penelitian sudah mempelajari sifat mekanik kulit dengan menggunakan berbagai metode $[8,9]$. Kulit sintetis harus mempunyai sifat mekanik yang cukup kuat ketika menerima beban tarik saat proses jahit, oleh karena itu penelitian yang mempelajari interaksi benang jahit dan kulit sintetik juga dilakukan [10]. 
Kulit manusia seringkali dimodelkan dengan sifat viskoelastik, yang berarti bahwa kulit dapat memanjang ketika ditarik, dan akan kembali ke posisi semula ketika dilepaskan [11]. Sifat ini mirip dengan sifat yang dimiliki oleh karet. Karet mempunyai sifat viskoelastik karena adanya rantai polimer yang saling diikat oleh crosslink dengan bantuan accelerator (contohnya sulfur), lihat Gambar 2. Karena struktur inilah sifat mekanik karet dipengaruhi oleh regangan dan waktu $[12,13]$. Kemiripan karakteristik karet dan kulit yang menjadikan karet sering digunakan sebagai material kulit sintetis, seperti pada telapak kaki tiruan [14] dan jari tiruan [15]. Berbeda dengan produk telapak kaki dan jari tiruan yang lebih mementingkan penampilan (kosmetik), prepusium sintetik lebih mementingkan sifat mekanik yang mendekati dengan aslinya untuk memberikan pengalaman memotong dan menjahit prepusium seperti aslinya. Walaupun beberapa penelitian sudah mempelajari sifat kulit dan material sintetisnya, tetapi belum ditemukan penelitian yang fokus pada kulit prepusium dan material sintetis yang menyerupai sifat prepusium.

Dalam penelitian ini, sifat mekanik prepusium akan dianalisis menggunakan Dynamic Mechanical Analyzer (DMA). Di sisi lain, beberapa kandidat kulit sintetis yang terbuat dari karet silikon akan dievaluasi oleh praktisi khitan untuk mengerucutkan kandidat material yang mempunyai feeling memotong dan menjahit yang mirip dengan kulit prepusium asli. Kandidat material tersebut kemudian diuji sifat mekaniknya dengan DMA dan dibandingkan hasilnya dengan sifat mekanik kulit prepusium.

\section{Material dan Metodologi}

\subsection{Material}

Prepusium didapatkan dari acara khitanan massal yang diselenggarakan di kota Cirebon, lihat Gambar 3a. Dari beberapa prepusium yang didapatkan, dipilih 3 prepusium yang kondisinya baik untuk dilakukan uji sifat mekanik. Prepusium mempunyai ketebalan yang bervariasi antara 2-3 $\mathrm{mm}$. Untuk mencegah pembusukan dan berubahnya sifat mekanik, prepusium disimpan dalam freezer sebelum dilakukan uji sifat mekanik.

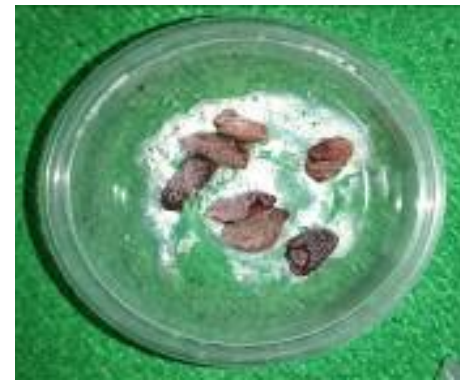

(a)

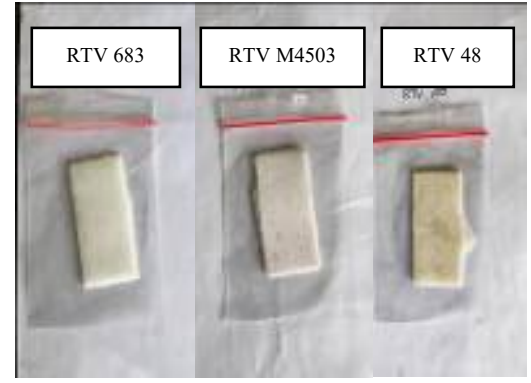

(b)

Gambar 3. (a) Prepusium dan (b) karet silikon.

Material prepusium sintetis menggunakan karet jenis silikon dengan pertimbangan mudah proses produksinya. Ada tiga jenis silikon yang dipilih sebagai kandidat prepusium sintetis yang ditunjukkan pada Gambar 3b, yaitu RTV (Room Temperature Vulcanizing) 683, RTV M4503, dan RTV 48. Ketiga karet silikon tersebut kemudian dibuat sampel dengan ukuran tebal $1.5 \mathrm{~mm}$, panjang $4 \mathrm{~cm}$ dan lebar $2 \mathrm{~cm}$. Pada tahap awal, ketiga sampel tersebut diobservasi oleh praktisi khitan untuk menentukan jenis silikon yang secara feeling memotong menyerupai aslinya. Salah satu feeling memotong yang penting dalam pembuatan prepusium sintetis adalah efek "kres" saat pemotongan. Berdasarkan hasil observasi dari beberapa praktisi, karet silikon jenis RTV M4503 dan RTV 48 yang paling mendekati feeling memotong prepusium. Kedua jenis karet silikon ini yang akan diuji lebih lanjut sifat mekaniknya. 


\subsection{Eksperimen}

Sifat mekanik material diuji dengan alat Dynamic Mechanical Analyzer (DMA) di Laboratorium Zat Padat, Departemen Fisika, Institut Teknologi Sepuluh November. DMA merupakan alat yang digunakan untuk mengukur sifat mekanik baik dalam kondisi statik maupun dinamik. Pada material yang mempunyai sifat viskoelastis, sifat mekaniknya berbeda ketika dalam kondisi statik dan dinamik. Dalam penelitian ini, pengujian DMA dilakukan dengan mode tarik karena pada aplikasi alat peraga khitan, prepusium sintetis akan ditarik sebelum dipotong. Gambar 4 menunjukkan proses pemasangan sampel pada DMA.

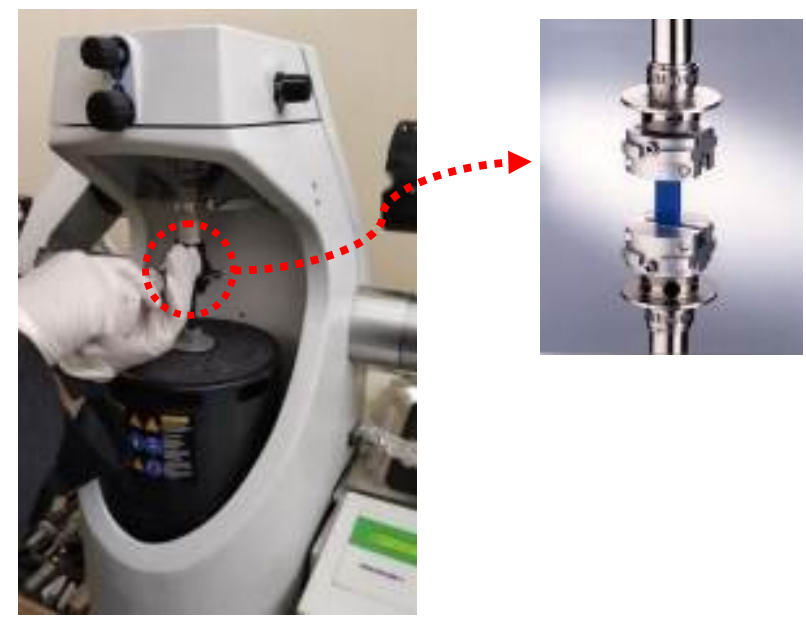

Gambar 4. Pemasangan sampel pada DMA dengan mode tarik.

Uji tarik dengan DMA akan menghasilkan modulus kompleks, karena gaya sinusoidal yang diberikan menghasilkan respon yang sinusiodal dengan mengalami ketertinggalan fasa (phase lag). Modulus kompleks mempunyai dua bagian, yaitu modulus penyimpanan (storage modulus) dan modulus hilang (loss modulus). Dalam penelitian ini, hanya menganalisis storage modulus yang dianggap ekuivalen dengan modulus elastisitas [13].

DMA yang digunakan pada penelitian ini adalah Mettler Toledo SDTA861e dengan metode pengukuran strain sweep. Pengujian DMA dilakukan pada suhu ruang $27^{\circ} \mathrm{C}$, frekuensi $1 \mathrm{~Hz}$, dan regangan dari 0-0,125\%. Dua sampel silikon disiapkan dengan dimensi panjang $20 \mathrm{~mm}$, lebar $5 \mathrm{~mm}$, dan tebal 1,5 mm. Sedangkan 3 sampel prepusium disiapkan dengan dimensi panjang $20 \mathrm{~cm}$, lebar $5 \mathrm{~mm}$, dan tebal bervariasi antara 2-3 $\mathrm{mm}$. Ketebalan prepusium tidak dilakukan pemotongan karena terkendala proses pemotongan ketebalan yang sulit.

\section{Hasil dan Pembahasan}

Hasil uji tarik dengan DMA pada tiga material prepusium dapat dilihat pada Gambar 4. Pada regangan kecil, nilai modulus elastisitas tinggi dan berangsur turun dengan bertambahnya regangan. Hal ini mengindikasikan bahwa prepusium mempunyai sifat viskoelastik. Kurva pada ketiga sampel prepusium menunjukkan variasi hasil yang sangat besar. Beberapa pengujian sebelumnya tentang sifat mekanik kulit juga menunjukkan hasil yang tidak seragam karena kompleksitas struktur kulit [16]. Berbagai faktor yang menyebabkan hal ini diantaranya umur anak dan genetik. Selain itu, dimensi tebal sampel kulit juga dapat mempengaruhi variasi hasil sifat mekanik dari ketiga prepusium. 


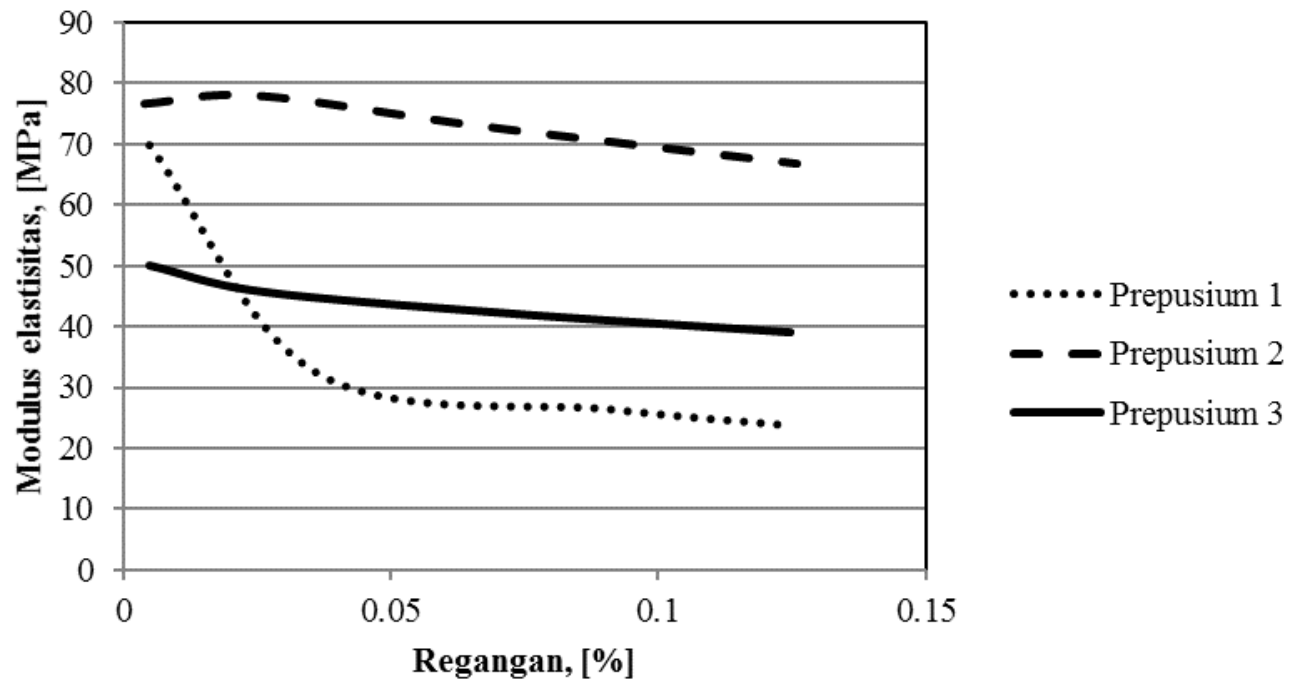

Gambar 4. Kurva modulus elastisitas terhadap regangan pada tiga sampel prepusium.

Gambar 5 menunjukkan kurva modulus elastisitas terhadap regangan pada dua sampel karet silikon. Pada gambar tersebut dapat dilihat bahwa tren kurva sama dengan yang terjadi pada sampel prepusium, yaitu modulus elastisitas tinggi pada rengangan kecil kemudian modulus elastisitas menurun seiring dengan bertambahnya regangan. Modulus elastisitas karet silikon RTV M4503 menunjukkan nilai yang lebih tinggi dibandingkan dengan karet silikon RTV 48, terutama pada regangan kecil.

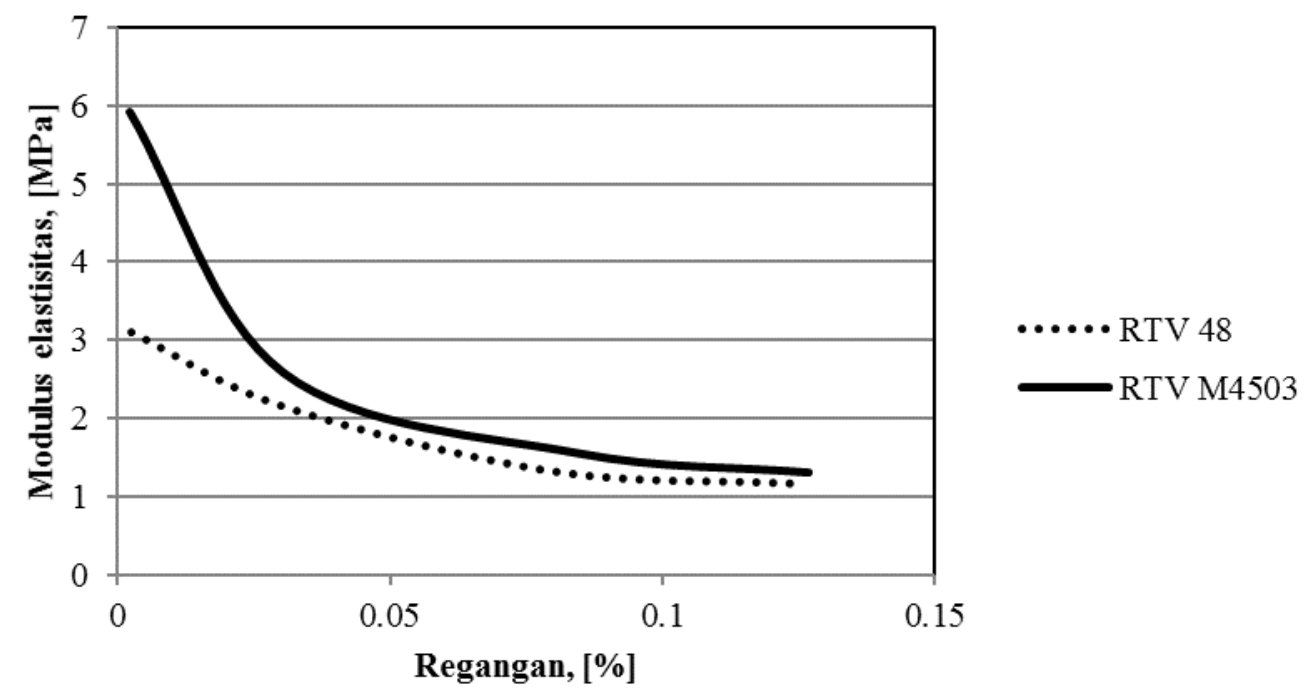

Gambar 5. Kurva modulus elastisitas terhadap regangan pada dua sampel karet silikon.

Gambar 4 dan Gambar 5 menunjukkan bahwa modulus elastisitas prepusium dan karet silikon mempunyai tren yang sama, tetapi nilai eksaknya berbeda. Walaupun menurut praktisi khitan feeling memotong kedua karet silikon sudah cukup mirip dengan aslinya, tetapi sifat mekaniknya menunjukkan nilai yang berbeda dibandingkan dengan prepusium. Hal ini dapat terjadi karena sulitnya mempersiapkan sampel prepusium dengan tebal yang seragam dan sesuai dengan standar. Perbedaan tebal ini dapat menjadi salah satu sumber kesalahan hasil DMA. Untuk mengurangi kesalahan 
tersebut, pengujian sifat mekanik dengan metode indentasi dapat menjadi salah satu opsi. Selain itu, nilai modulus elastisitas pada regangan yang lebih besar perlu diobservasi lebih lanjut mengingat prepusium ditarik dengan regangan besar sebelum dipotong, seperti yang ditunjukkan pada Gambar 1.

\section{Kesimpulan}

Sifat mekanik prepusium dan karet silikon telah dipelajari menggunakan DMA. Pengujian dengan mode tarik dipilih untuk merepresentasikan proses yang terjadi pada proses khitan. Pemilihan awal karet silikon berdasarkan asesmen dari praktisi khitan pada material karet silikon yang mempunyai feeling proses memotong mirip dengan aslinya. Terdapat dua kandidat material kulit sintetis yang terpilih, yaitu RTV M4503 dan RTV 48. Hasil pengujian menunjukkan bahwa modulus elastisitas tiga prepusium yang diuji mempunyai nilai yang bervariasi. Sedangkan modulus elastisitas RTV M4503 menunjukkan nilai lebih tinggi dibanding dengan RTV 48. Kurva modulus elastisitas terhadap regangan pada prepusium dan karet silikon menunjukkan tren yang sama, tetapi nilai eksak modulus elastisitas prepusium lebih tinggi dibanding dengan karet silikon.

\section{Ucapan terima kasih}

Penulis mengucapkan terimakasih kepada Program Studi Teknik Mesin Universitas Islam Indonesia sebagai pemberi dana dalam penelitian ini.

\section{Daftar Pustaka}

[1] Seleim HM, Elbarbary MM. Major penile injuries as a result of cautery during newborn circumcision. Journal of pediatric surgery. 2016;51(9):1532-7.

[2] Kaggwa S, Galukande M. Male genital mutilation (amputation) and its complications: a case report. J BMC research notes. 2014;7(1):1-3.

[3] Roca P, Alvarado C, Stausmire JM, Farooq S, Hill-Engstler EA. Effectiveness of a Simulated Training Model for Procedural Skill Demonstration in Neonatal Circumcision. Simulation in Healthcare. 2012;7(6):362-73.

[4] Brill JR, Wallace B. Neonatal circumcision model and competency evaluation for family medicine residents. J FAMILY MEDICINE-KANSAS CITY-. 2007;39(4):241.

[5] A.P. N. Teknik Sirkumsisi 2011 [Available from: http://www.poltekkes-malang.ac.id/index.php/sugeng/cetak/174.

[6] Coran AY. Chapter 7 - Vulcanization. In: Mark JE, Erman B, Roland CM, editors. The Science and Technology of Rubber (Fourth Edition). Boston: Academic Press; 2013. p. 337-81.

[7] Kalangi SJ. Histofisiologi kulit. JURNAL BIOMEDIK: JBM. 2013;5(3).

[8] Abas WW, Barbenel J. Uniaxial tension test of human skin in vivo. Journal of biomedical engineering. 1982;4(1):65-71.

[9] Manan NFA, Mahmud J, Ismail MH, Vol B. Quantifying the biomechanical properties of bovine skin under uniaxial tension. Journal of Medical. 2013;2(1).

[10] Zhang G, Ren T, Zeng X, Van Der Heide E. Influence of surgical suture properties on the tribological interactions with artificial skin by a capstan experiment approach. Friction. 2017;5(1):87-98.

[11] Khatyr F, Imberdis C, Vescovo P, Varchon D, Lagarde JM, technology. Model of the viscoelastic behaviour of skin in vivo and study of anisotropy. Skin research. 2004;10(2):96-103. 
[12] Khafidh M, Rodriguez NV, Masen MA, Schipper DJ. The dynamic contact area of elastomers at different velocities. Tribology-Materials, Surfaces Interfaces. 2016;10(2):70-3.

[13] Khafidh M. Friction, Wear and Noise of Short-cut Aramid Fibre Reinforced Elastomers in Sliding Contacts [PhD Thesis]. Enschede, The Netherlands: University of Twente; 2019.

[14] Sasaki K, Pinitlertsakun J, Rattanakoch J, Sukthomya S, Guerra G, Latt T, et al. The development and testing of a modified natural rubber CR solid ankle-cushion heel prosthetic foot for developing countries. Journal of Rehabilitation Assistive Technologies Engineering. 2017;4:2055668317712978.

[15] White RC, Bowen D, Dumbalska T, Hoeger K, Mok AY. Two left hands, ten interlaced fingers: a new rubber hand illusion. Perception. 2016;45(3):346-9.

[16] Mohd Noor SNA, Mahmud J, editors. A review on synthetic skin: materials investigation, experimentation and simulation. Advanced materials research; 2014: Trans Tech Publ. 